\title{
Analysis of the Microstructure and Mechanical Properties during Inertia Friction Welding of the Near-a TA19 Titanium Alloy
}

Yanquan Wu' ${ }^{1}$, Chunbo Zhang ${ }^{1,2}$, Jun Zhou ${ }^{1 *}$, Wu Liang ${ }^{1}$ and Yunlei Li ${ }^{1}$

\begin{abstract}
The current research of titanium alloy on friction welding process in the field of aero-engines mainly focuses on the linear friction welding. Compared to the linear friction welding, inertial friction welding of titanium alloy still has important application position in the welding of aero-engine rotating assembly. However, up to now, few reports on inertial friction welding of titanium alloy are found. In this paper, the near-alpha TA19 titanium alloy welded joint was successfully obtained by inertial friction welding (IFW) process. The microstructures and mechanical properties were investigated systematically. Results showed that the refined grains within 15-20 $\mu \mathrm{m}$ and weak texture were found in the weld zone due to dynamic recrystallization caused by high temperature and plastic deformation. The weld zone consisted of acicular $\alpha^{\prime}$ martensite phase, $a_{p}$ phase and metastable $\beta$ phase. Most lath-shaped $a_{s}$ and $\beta$ phase in base metal were transformed into acicular martensite $\alpha^{\prime}$ phase and metastable $\beta$ phase in thermo-mechanically affected zone and heat affected zone. As a result, the microhardness of welded joint gradually decreased from the weld zone to the base metal. Tensile specimens in room temperature and high temperature of $480^{\circ} \mathrm{C}$ were all fractured in base metal illustrating that the inertia friction welded TA19 titanium alloy joint owned higher tensile strength compared to the base metal.
\end{abstract}

Keywords: Inertia friction welding, TA19, Microstructure, Mechanical property, Texture

\section{Introduction}

Titanium alloys, as a significant structural metal material, are widely applied in aerospace and other fields owing to its low density, high specific strength, low elastic modulus, excellent corrosion resistance and high heat resistance [1-5]. Ti-6Al-4V alloy is first applied in engineering field and the different titanium alloys play important roles in modern industries with the development of metallurgical techniques [6-10]. For the past few years, the requirement of high performance titanium alloy was increased in the aero-engine fan systems and compressor

\footnotetext{
*Correspondence: mch_zhoujun@126.com

${ }^{1}$ Research and Development Center, Harbin Welding Institute Limited Company, Harbin 150028, China

Full list of author information is available at the end of the article
}

components because of the improvement of thrust-toweight ratio of aero-engines $[11,12]$. Thus, a variety of high performance titanium alloys have been developed to satisfy the demand of aero-engines to high temperature components [13-15].

Inertial friction welding (IFW), as a solid state welding procedure, has the advantages of fewer process parameters, low heat input, small deformation and narrow welding seam $[16,17]$. In addition, high quality, high efficient, environmental friendliness, and precise power input control are well reflected in IFW. Compared with the fusion welding, the defects such as oxidation slag inclusion, poor fusion, lack of penetration and solidification cracks can be avoided effectively by IFW with the temperature lower than melting point and sufficient plastic deformation 
[18]. Thus, the IFW process is quite suitable for the welding of the axisymmetric components of homogeneous and heterogeneous "difficult-to-weld" material [19], such as nickel superalloys [20-22], titanium alloys [23, 24] and intermetallic materials [25]. Besides, the stress concentration of bolt hole can be eliminated by welded joint. Up to date, IFW has become an important manufacturing process for compressor and high pressure turbine in advanced aero-engines [26]. In addition, the IFW process is also widely used in other important industrial fields $[27,28]$.

Compared with near- $\beta$ titanium alloy and $\alpha+\beta$ titanium alloy, the $\alpha$ and near- $\alpha$ titanium alloys can retain its strength, creep resistance and microstructure stability at high temperature. Thus, the near- $\alpha$ titanium alloys has been widely used in the components in compressor and fan system of advanced areo-engines. The friction welding of near $-\beta$ and $\alpha+\beta$ titanium alloys, such as Ti6Al4V, Ti6246, Ti17, and so on has been widely investigated in nearly research. Liu et al. [29] researched the texture evolution in $\alpha+\beta$ titanium alloy joint by thermal and mechanical of inertia friction welding. The result showed that the texture of substantial remnant $\beta$ in the thermomechanical affected zone was $<100>$ fiber texture and $<111>$ fiber texture in the dynamic recrystallization zone. Ballat-Durand et al. [30] found that the $\beta \rightarrow \alpha^{\prime}$ martensitic transformations during cooling resulted in a strong texture in the core of the joint with the $\{0001\}$ plane paralleling with the friction plane $\{x y\}$, and the $<1120>$ direction aligning with the transversal direction $\langle\mathrm{X}\rangle$ when they researched the microstructure changes during linear friction welding of Ti6242 titanium alloy. The effect of friction times to ultimate tensile strength and microstructure of welded tubes was investigated by Palanivel et al. [31], in which, the rate of deformation increased with friction time and refined the grains in the weld zone and coarse grains structure was formed in the weld zone and heat affected zone from the center towards the flash. However, the reports on IFW of near- $\alpha$ titanium alloys is limited. Besides, the investigation on microstructure texture and mechanical properties in IFW of TA19 titanium alloy is hardly found. As one of the near- $\alpha$ titanium alloys, TA19 alloy has excellent tensile strength, toughness and high temperature creep resistance [32]. Till now, previous studies on the TA19 titanium alloy were mainly focused on the microstructure and mechanical properties in itself at different heat treatment conditions [33-37]. However, limited reports have taken attention to the welding process of TA19 titanium alloy, especially friction welding process. Song et al. [38] found that the fatigue property of electron beam welding joint of TA19 titanium alloy was better than that of base metal at room temperature. The TA19 titanium alloy was welded with the linear friction welding by Zhang et al. [39], in which a typical dynamic recrystallization microstructure in weld zone, consisting of $\alpha^{\prime}$ martensite and acicular $\alpha$ phase within equiaxial grains was found. Zhang et al. [40] only investigated the weldability of TA19 alloy in IFW and preliminarily analyzed the microstructure of the welded joint.

Therefore, the main aim in the current work is to study the microstructure evolution and mechanical properties in IFW of TA19 alloy. The analysis of microstructures highlights the strengthening mechanism, which affects the mechanical properties. The findings in the work will provide key experimental date and theoretical guidance for inertia friction welding of TA19 alloy in industrial application.

\section{Materials and Methods}

The HSMZ-130 axial and radial IFW machine selfdesigned by Harbin Welding Institute Limited Company (China) was used to join the TA19 titanium alloy pipes, with a outer diameter and wall thickness of $170 \mathrm{~mm}$ and $50 \mathrm{~mm}$, respectively. The heat treatment of TA19 titanium alloy in this study was solution treated with $995^{\circ} \mathrm{C}$ for $1 \mathrm{~h}$, and its nominal chemical composition was shown in Table 1 . The microstructure of TA19 alloy analyzed by optical microscope $(\mathrm{OM})$ and scanning electron microscope (SEM) was shown in Figure 1. Figure 2 revealed the pattern of X-ray diffraction analysis in TA19 alloy. The typical bimodal microstructure of the base material can be observed in Figure 1(b), which consists of the equiaxial prior $\alpha\left(\alpha_{p}\right)$ phase, the lamellar secondary $\alpha\left(\alpha_{s}\right)$ phase and the thin $\beta$ phase. The average size of prior- $\beta$ grains was approximately $30 \mu \mathrm{m}$.

According to the previous study [40], the IFW parameters were determined as the initial rotation speed of 500 $\mathrm{r} / \mathrm{min}$, friction pressure of $50 \mathrm{MPa}$, upsetting pressure of $80 \mathrm{MPa}$ and the moment of inertia of $388 \mathrm{~kg} \cdot \mathrm{m}^{2}$. Prior to welding, the welding surface of the workpieces were cleaned by alcohol. The appearance of welded joint with uniform curling flash was displayed in Figure 3. The obvious longitudinal and circumferential cracks could not be found from the welded joint, which demonstrated that

Table 1 Nominal chemical composition of TA19 (wt\%)

\begin{tabular}{llllllllll}
\hline Element & Ti & Al & Zr & Sn & Mo & Si & Fe & C & N \\
\hline $\mathrm{W} t \%$ & Bal & 6.2 & 4.1 & 1.9 & 2.0 & 0.07 & 0.01 & 0.003 & 0.006 \\
\hline
\end{tabular}



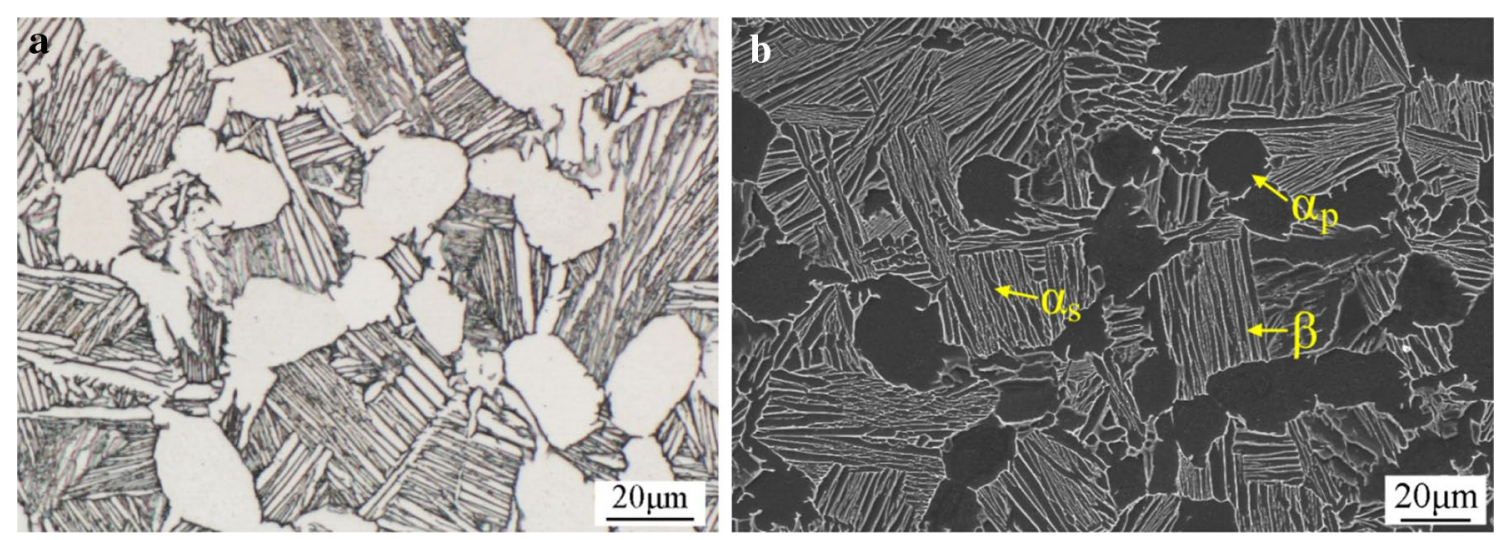

Figure 1 Microstructure of TA19 titanium alloy base metal: (a) OM and (b) SEM

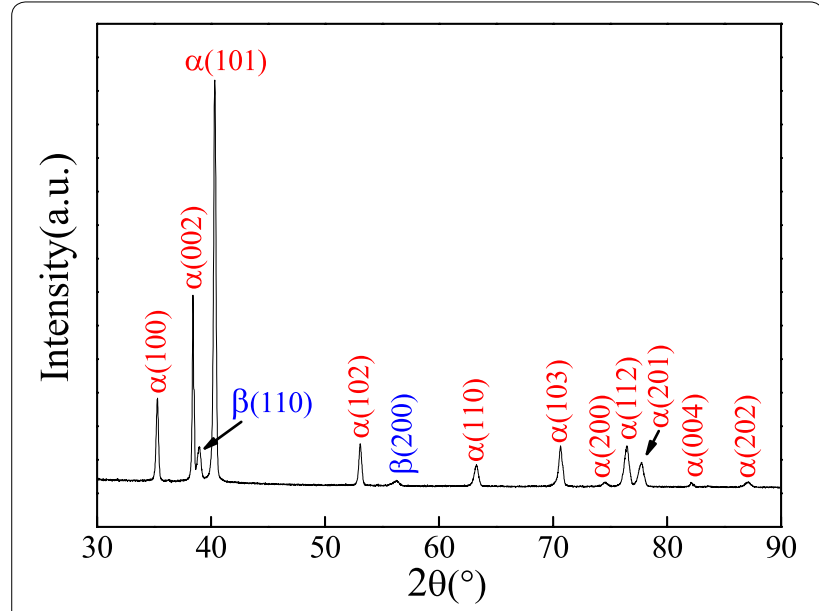

Figure 2 X-ray diffraction analysis of TA 19 titanium alloy

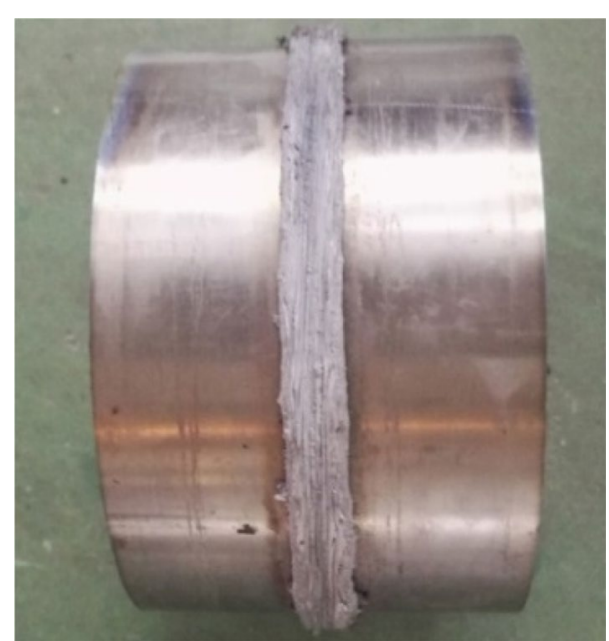

Figure 3 Appearance of the TA19 welded joint

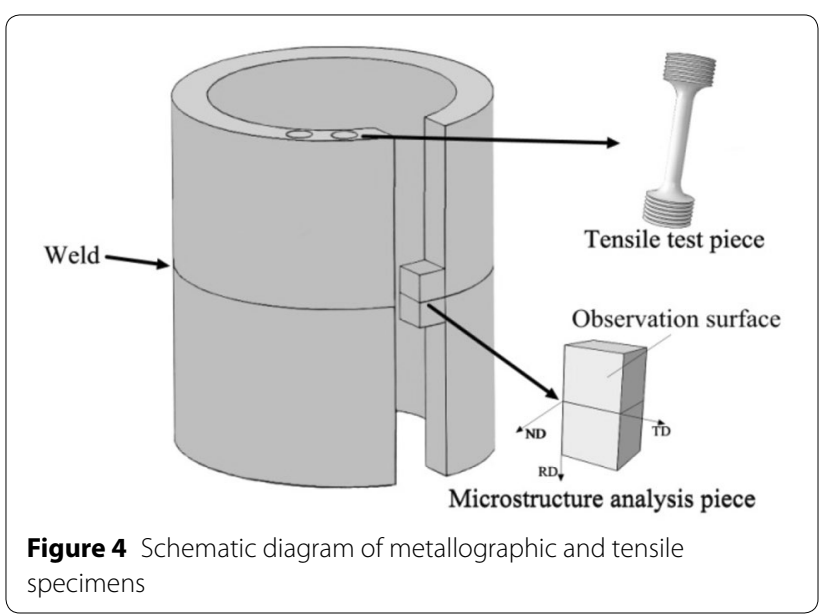

the TA19 titanium alloy was successfully joined. However, the surface of flash was relatively rough, which was characterized as the morphology of burr.

Figure 4 showed the schematic diagram of samples prepared for microstructure analysis and performance tests. The block samples were used to perform the metallurgical examination. The polished metallographic specimen was etched in Kroll's agent (2\% $\mathrm{HF}, 8 \% \mathrm{HNO}_{3}$ and $90 \%$ $\mathrm{H}_{2} \mathrm{O}$ ). The specimen of EBSD analysis was first polished mechanically and then processed by IB-09020CP section ion polishing instrument. The bar samples used for the tensile tests were cut from the welded joint according to ASTM E8 at room temperature and ASTM E21 at high temperature of $480{ }^{\circ} \mathrm{C}$.

The microstructure morphology, phase composition and grain characteristics were examined by SEM with electron backscattered diffraction (EBSD). The microhardness of welded joint was measured at the Vicker's indentation hardness tester using a load of $0.2 \mathrm{~kg}$ with a dwell time of $10 \mathrm{~s}$. The distance between two indentation 
points was set to $0.2 \mathrm{~mm}$. The model number of the machine is HVS-1000A.

\section{Results and Discussion}

\subsection{Microstructure}

Figure 5 shows morphology of different microstructure zones across the welded joint along the axial of welded specimens. The microstructural zones showed symmetrical distribution on both sides of the weld interface due to the similar thermo-mechanical condition during IFW. The weld zone (WZ), thermo-mechanically affected zone (TMAZ), heat affected zone (HAZ) and base metal (BM) can be clearly distinguished from the welded joint. However, it is difficult to observe the TMAZ in IFW of Ti6246 with a higher upsetting pressure [41]. The WZ is also characterized as dynamically recrystallized region or transformed and recrystallized zone, where the materials experience a thermal-mechanical deformation above $\beta$-transus temperature [42]. The width of WZ is approximately $1.6 \mathrm{~mm}$ under current welding process parameter. At the same time, the weld line with the width of about $100 \mu \mathrm{m}$ in the center of WZ can be clearly seen which displayed a slightly darker color compared with zones in Figure 4. The darker color of weld line indicates that the corrosion resistance may be poor. With the width of approximately $900 \mu \mathrm{m}$ on both sides of the WZ, the TMAZ has been clearly demonstrated by the transmutative $\alpha_{p}$ phase which is extruded roblike and approximate paralleling to the weld line under thermo-mechanical coupling process. In addition, the width of TMAZ is obviously narrower than the WZ, which can be related to the changing of temperature gradient. The boundary line between HAZ and BM is relatively blurred as shown in Figure 5, because these two zones undergo a lower temperature and the effect of plastic deformation is quite weak compared with WZ and TMAZ. Thus, the grain size and morphology in HAZ are basically similar to those of the BM. Based on the area of dark region which mainly represents the $\alpha_{p}$ phase, the content of $\alpha_{p}$ phase in the HAZ on the left side of WZ is obviously higher than that at the right side. This phenomenon can be attributed to different temperatures distribution on both sides of the WZ due to the difference of thermal boundary condition.

\subsubsection{Weld Zone}

The microstructure and morphology characteristics of the $\mathrm{WZ}$ are showed in Figure 6. It can be clearly seen that the microstructure in $\mathrm{WZ}$ is completely different from that in the BM, which is illustrated in Figure 1. The equiaxial $\alpha_{\mathrm{p}}$ phase and the lamellar $\alpha_{\mathrm{s}}$ phase disappear in the WZ during IFW. Compared with that in the $\mathrm{BM}$, the grains in the WZ have been refined. The size of fine and equiaxial grains ranges from $15 \mu \mathrm{m}$ to $20 \mu \mathrm{m}$ approximately. Additionally, the sizes of some grains are relatively finer than those of the BM, indicating the occurrence of dynamic recrystallization owing to the high temperature and plastic deformation in WZ. At the same time, a mass of acicular $\alpha^{\prime}$ martensite phases are transformed from the $\beta$ phase at elevated temperature through the non-diffusive transformation due to the rapid cooling rate after welding, which show a cross distribution in the WZ. The width of acicular $\alpha^{\prime}$ martensite phase is only $0.5-1 \mu \mathrm{m}$, which is far less than that of $\alpha_{\mathrm{s}}$ phase in the BM. Furthermore, the cross angle of acicular $\alpha^{\prime}$ martensite phase is approximately $60^{\circ}$ as shown in Figure $6(\mathrm{~b})$. Some $\alpha_{\mathrm{p}}$ phases with the size of about $5 \mu \mathrm{m}$ were formed along the grain boundary by the diffusive transformation when the welding temperature is below the $\beta$-transus in the WZ. In addition, a small amount of metastable $\beta$ phases with the layer structure are retained near some grains boundary, which is the result of rapid cooling after welding.

Figure 7 further shows the microstructure information in the WZ, which is examined by EBSD technique.

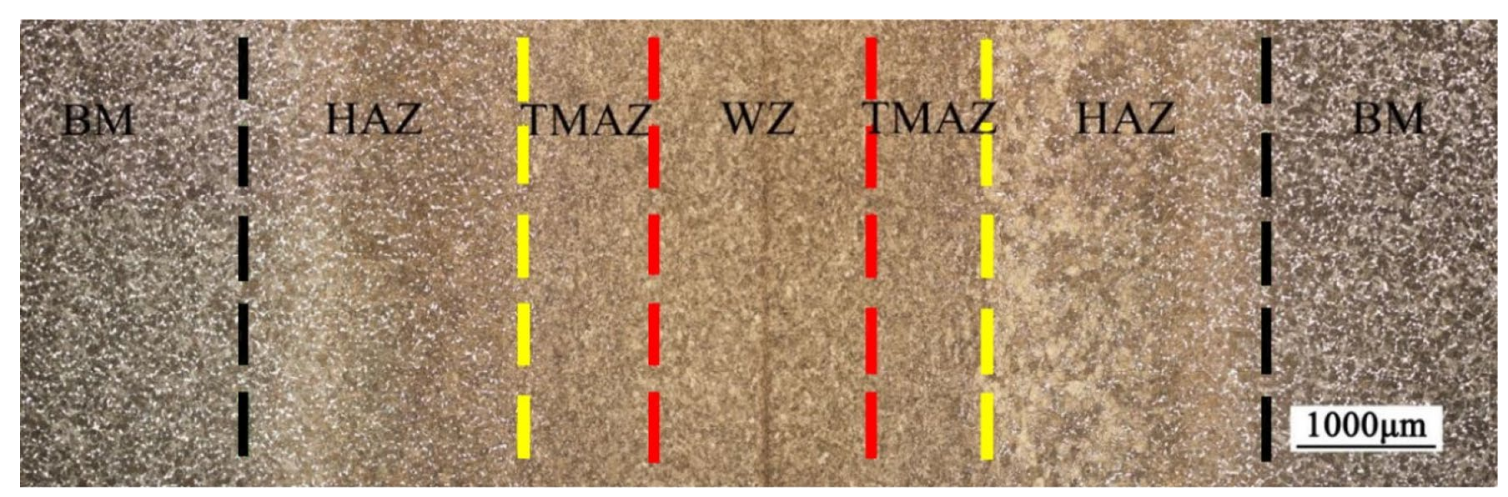

Figure 5 Microstructure of the inertia friction welded TA19 joint 

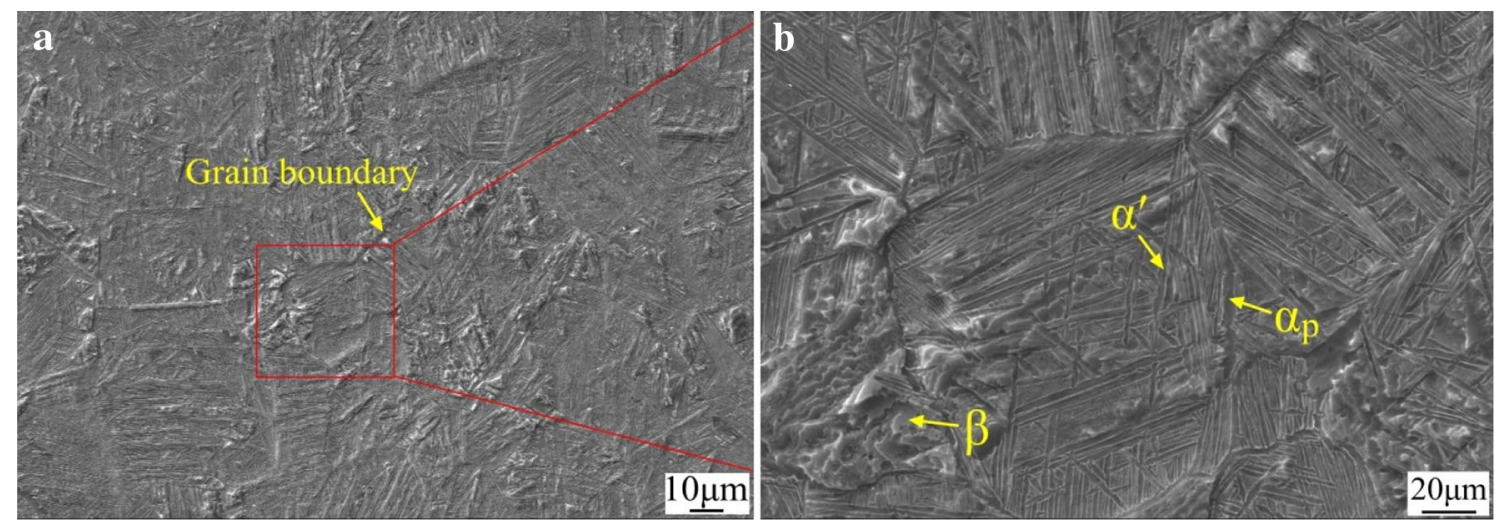

Figure 6 Typical microstructure of weld zone: a Low magnification, and $\mathbf{b}$ high magnification

The grain misorientation angle map of $\mathrm{WZ}$ and $\mathrm{BM}$ are showed in Figures $7(\mathrm{a}-\mathrm{c})$, respectively. The red and black lines express the high-angle grain boundaries (HAGBs, $>15^{\circ}$ ) and low-angle grain boundaries (LAGBs, $<15^{\circ}$ ), respectively. It can be clearly observed from Figure $7(\mathrm{a}, \mathrm{b})$ that the HAGBs with percentage of $57.9 \%$ feature primarily in the $\mathrm{WZ}$ through statistical calculations. However, the density of HAGBs is lower than that of BM with number percentage of $69.7 \%$ as shown in Figure $7(\mathrm{c})$, which indicates that the number of LAGBs is increased by the dynamic recrystallization during IFW. In general, LAGBs would transform into HAGBs with the proceeding of dynamic recrystallization in the welding process [43]. However, the insufficient dynamic recrystallization in $\mathrm{WZ}$ will happen because of the rapid heating and cooling rate of IFW, which resulting in the formation of a mass of sub-structures within grains. Thus, the density of LAGBs in WZ is increased in IFW.

Figure $7(\mathrm{~d})$ presents the phase composition distribution in WZ, where $\alpha$ phase and $\beta$ phase are showed by using red and blue, respectively. It can be clearly seen that the WZ is mainly consisted of $\alpha$ phase. The percent of $\beta$ phase in $\mathrm{WZ}$ is $0.8 \%$ exceeding that of $\mathrm{BM}$, which indicates that more $\beta$ phases are saved in WZ. Some reports indicate that the friction interface temperature reaches above $1200{ }^{\circ} \mathrm{C}$, which exceed the nominal $\beta$-transus temperatures $[44,45]$. In addition, it also can be demonstrated by the disappear of equiaxial $\alpha_{p}$ phase from the Figure 6 because of the higher transition temperature of $\alpha_{p}$ phase compared with the $\alpha_{\mathrm{s}}$ phase. More $\beta$ phases are retained in WZ owing to a rapid cooling, in which an insufficient diffusion phase transition occurred. Furthermore, the residual $\beta$ phases of lamellar structure located at partial grain boundary in Figure 6(b) also are clearly found in Figure 7(d).
The $\beta$ phase can be ignored due to the much higher fraction of $\alpha$ phase than the fraction of $\beta$ phase in WZ. Thus, the inverse pole figure of only $\alpha$ phase in $\mathrm{WZ}$ is displayed in Figure 7(e). The crystallographic directions of different grains relative to the normal direction are indicated through different colors. It can be seen that fine and equiaxial grains in WZ show multifarious crystal orientation. However, the number of grains with [-12-10] direction is much higher than that of other grains in crystal orientation, which indicates that weak texture with [-12-10] direction in WZ is produced through dynamic recrystallization in IFW.

As shown in Figure 8, the figures of $\alpha$ phase pole are adopted to indicate the characteristic information. It can be seen that the $\{0001\}$ and $\{11-20\}$ pole figure exhibit nearly symmetrical poles distribution and have much higher density points compared with $\{10-10\}$ pole figure, which indicate the formation of several texture. This is because that the original grains have been replaced with dynamic recrystallized grains in different orientation distribution [46]. In addition, the highest poles intensity point of 13.27 times is distributed in $90^{\circ}$ from the ND towards the RD in the $\{0001\}$ pole figures, which further demonstrate the existence of texture with [-12-10] direction as shown in Figure 7e).

\subsubsection{Thermo-Mechanically Affected Zone}

Figure 9 exhibits the overall morphology of the TMAZ, and the typical microstructures of TMAZ close to WZ and HAZ. It can be clearly seen that the microstructure morphology of TMAZ has an obvious change compared to the BM. The fraction of $\alpha_{p}$ phase is gradually increased from the WZ to the HAZ. In addition, the equiaxial $\alpha_{\mathrm{p}}$ phase has been transformed into the rod under the effect of welding pressure and thermal cycling. This is due to that the temperature of TMAZ is lower than that of 

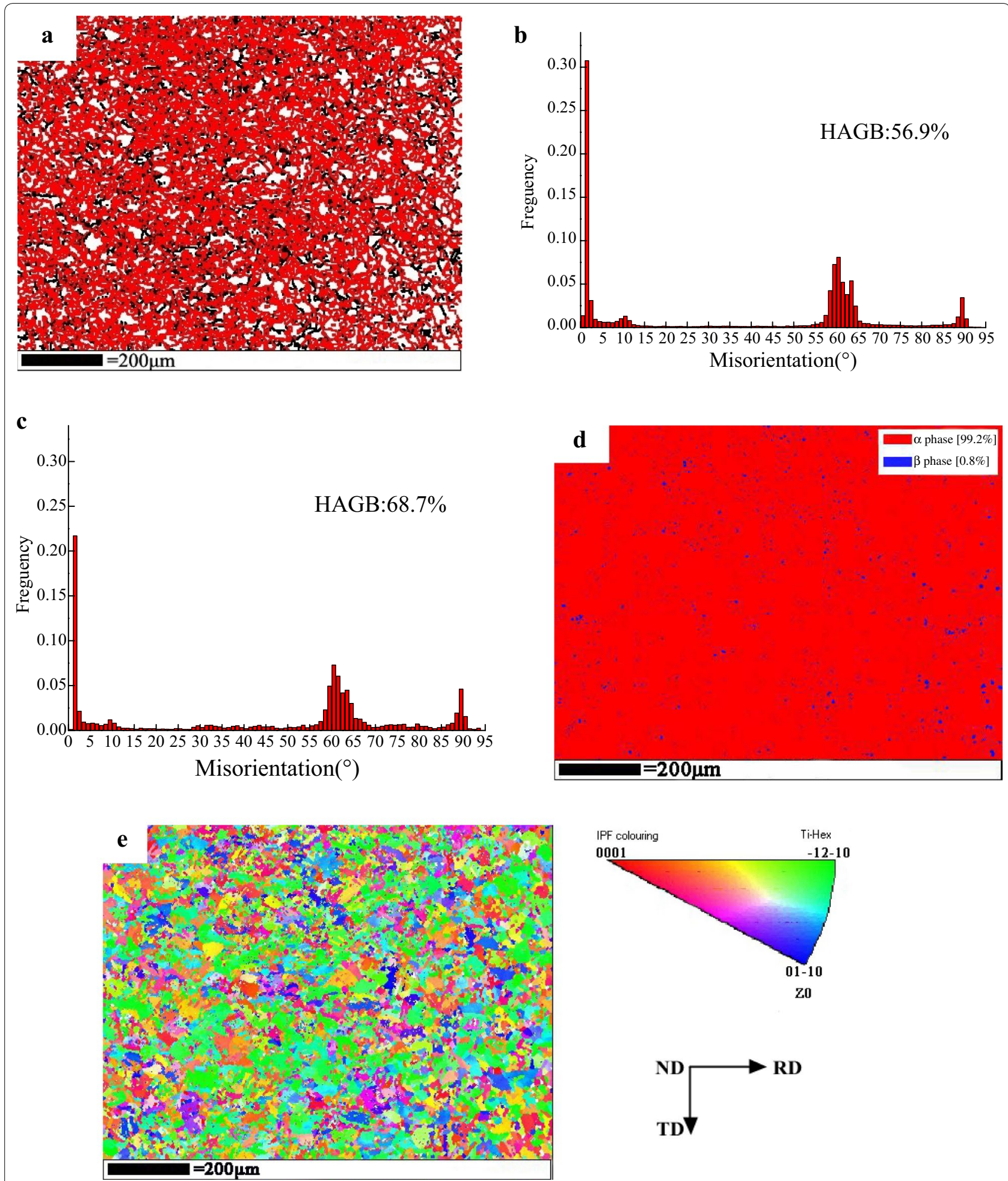

Figure 7 EBSD maps of weld zone: a Grain boundary misorientation angle; $\mathbf{b}$ Misorientation angle distribution of WZ; c Misorientation angle distribution of base material; $\mathbf{d}$ Phase distribution map; e Inverse pole figure 

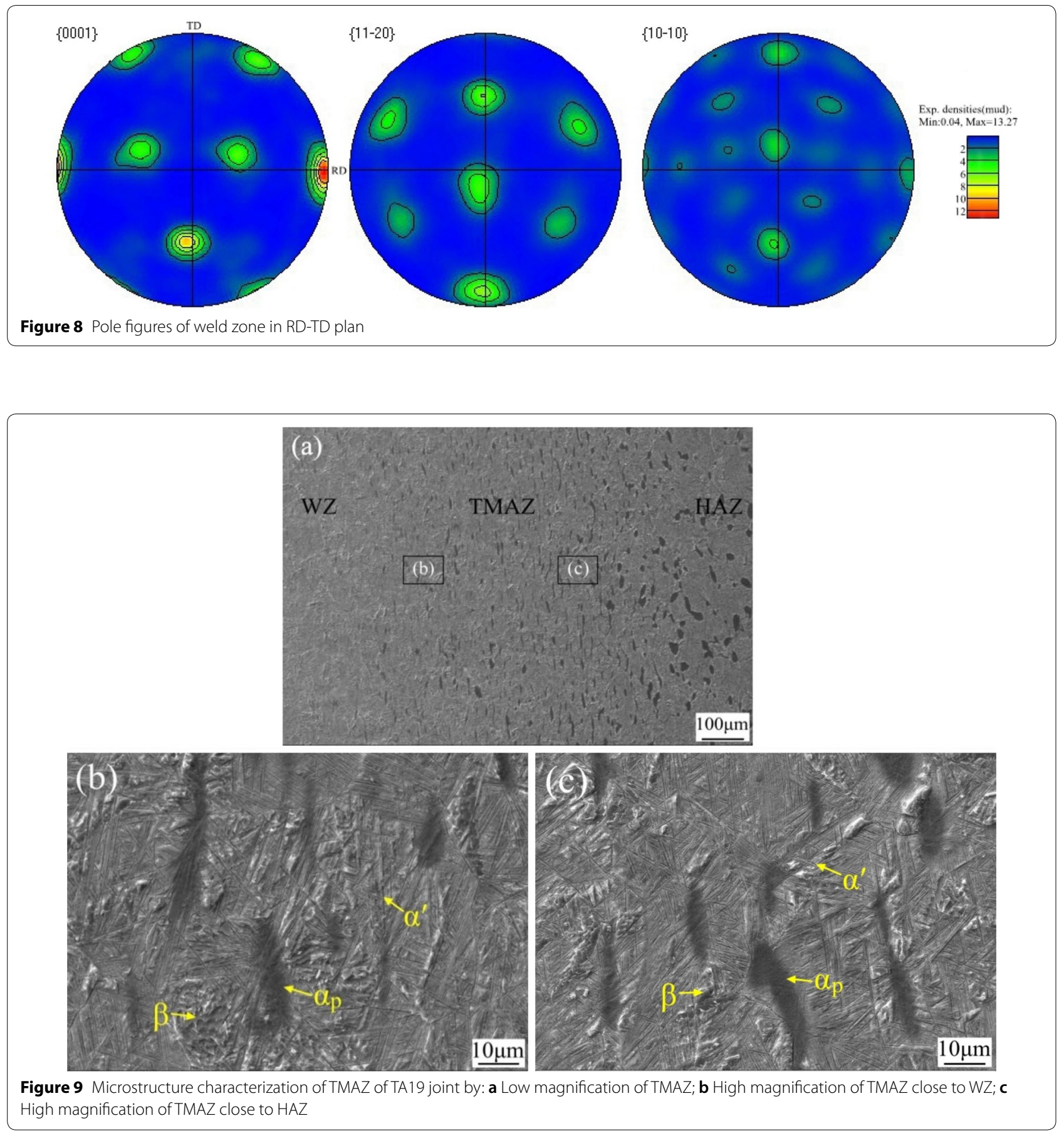

WZ, and $\alpha_{p}$ phase has not enough time to complete the microstructure transformation in IFW process. At the same time, the hardness of $\alpha_{p}$ phase is also decreased at high temperature. Thus, the shape of $\alpha_{p}$ phase is changed under the effect of high temperature and plastic deformation. The size of TMAZ with approximately $0.9 \mathrm{~mm}$ is narrower than that of $\mathrm{WZ}$, which may be due to an exorbitant heat input and welding pressure. Figure 9(b, c) show the high magnification SEM images close to WZ and HAZ, respectively. By contrasting the two images, the microstructures are basically the same, which are consisted of acicular $\alpha^{\prime}$ martensite phase, deformed $\alpha_{p}$ phase and metastable $\beta$ phase. However, the boundary of $\alpha_{\mathrm{p}}$ phase and $\beta$ grains close to WZ is relatively blurred compared with that far from WZ, which indicate that the temperature close to $\mathrm{WZ}$ is much higher than that far 
from $\mathrm{WZ}$ and exceed the $\beta$-transus temperature. Therefore, partial $\alpha_{\mathrm{p}}$ phases in boundary region are transformed into the $\beta$ phase at a short time. Nevertheless, because of the drop of temperature close to HAZ, the transformation of $\alpha_{p}$ phase is suppressed.

\subsubsection{Heat Affected Zone}

Figure 10 shows the microstructure of the HAZ. It can be clearly observed from the Figure 10(a) that grain size and morphology of $\alpha_{p}$ phase in HAZ are basically as same as those in BM without obvious change, which indicate that the HAZ is hardly influenced through the high temperature and plastic deformation in IFW. However, the lath $\alpha_{s}$ phase and $\beta$ phase can't be clearly distinguished compared with those in the BM as shown in Figure 10(a). The result shows that the temperature in HAZ is higher than the transition temperature of $\alpha_{s} \rightarrow \beta$ phase, so that the microstructures within $\beta$ grains are changed under welding thermal cycle. As the high magnification image in HAZ shown in Figure 10(b), the microstructure and morphology are completely different because of the effect of welding thermal cycle compared with those in the BM. A large number of fine and acicular $\alpha$ ' martensite phases of parallel or intersecting distribution can be clearly observed within original $\beta$ grains. The cross angle of acicular $\alpha$ ' martensite phase is about $60^{\circ}$. Nevertheless, the size of acicular $\alpha^{\prime}$ martensite phase in HAZ is smaller than that of TMAZ. This is because the HAZ has a faster cooling rate than the WZ and TMAZ due to its closeness to the BM with lower temperature. Thus, these fine and acicular $\alpha$ ' martensite phases in HAZ are produced through nondiffusive transformation of $\beta$ phases. The formation of mass $\alpha$ ' martensite phase in HAZ shows that welding heat input is excessive under welding parameters. Furthermore, the phenomenon of outward expansion of grain boundary based on the original grain boundary are found in HAZ as shown in Figure 10(b), which also indicates that grain has grown owing to higher energy input. New grains boundary is easily formed near the original grain boundary according to heterogeneous nucleation mechanisms. Besides, because of the rapid heating and cooling in IFW process and lower temperature in HAZ compared with that in WZ and TMAZ, the lamellar $\alpha_{p}$ phases of original grain boundary have not enough time and driving force to complete the phase transition and are retained. However, owing to the growth of grain and the formation of a mass of acicular $\alpha$ ' martensite phases, the fatigue property of the HAZ can be impaired and becomes a weakness zone of the welded joint. At the same time, because of the rapid cooling rate, the more metastable $\beta$ phases are also remained in HAZ as shown in Figure 10(b). This test result is also demonstrated through the EBSD techniques as shown in Figure 11.

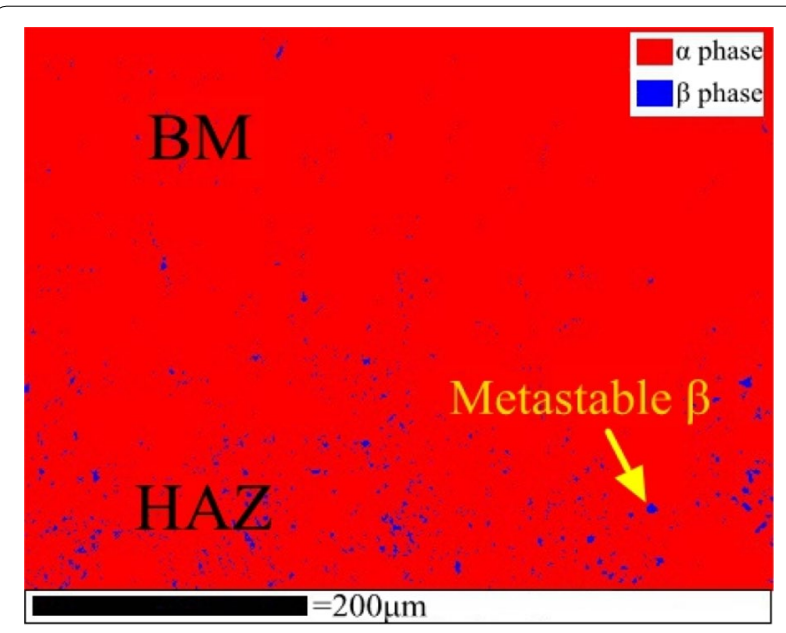

Figure 11 Phase distribution map in HAZ and base material by EBSD
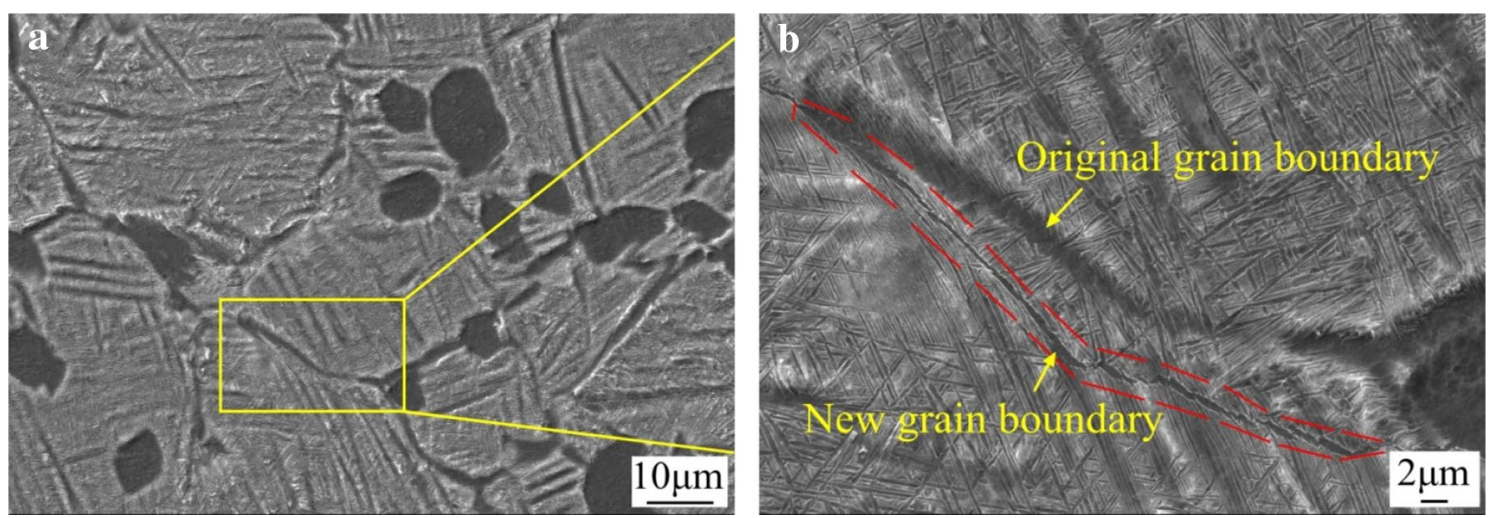

Figure 10 Microstructure characterization of HAZ: a Low magnification, and $\mathbf{b}$ High magnification 


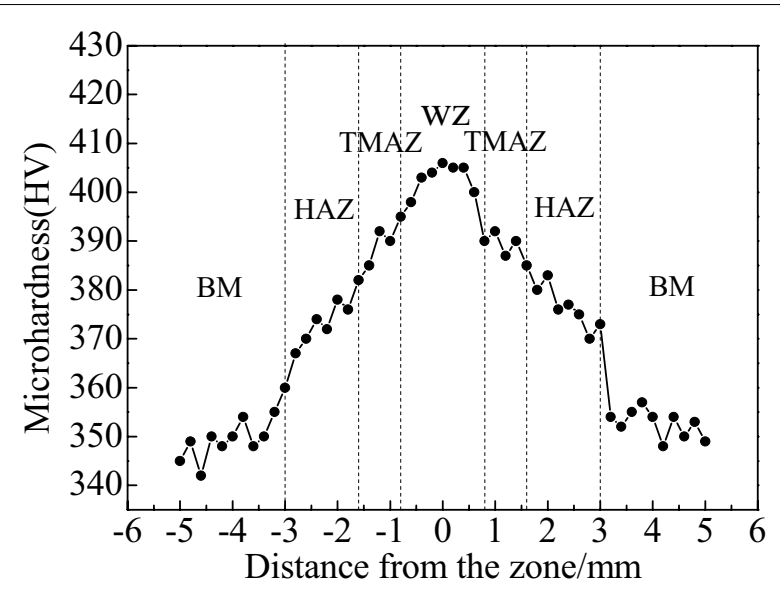

Figure 12 Microhardness profiles of the joint from weld zone to base metal

\subsection{Mechanical Properties}

\subsubsection{Microhardness}

Figure 12 presents the microhardness profiles of welded joint of TA19 alloy. The variation of microhardness is showed from the weld line in WZ to BM on both sides of welded joint, which demonstrates an approximate $\wedge$ shape profile. It can be clearly observed that the variation tendency of microhardness in different zones of welded joint is especially obvious. The highest microhardness has been observed in WZ, with an average value of approximately $400 \mathrm{HV}$. At the same time, the microhardness gradually decreases with increasing distance from the WZ to the BM. The high hardness in WZ should be attributed to the formation of fine and equiaxial grains and a mass of acicular $\alpha^{\prime}$ martensite phases, as the closepacked hexagonal $\alpha$ phase has a higher microhardness than the cubic $\beta$ phase [47]. However, a mass of fine and acicular $\alpha^{\prime}$ martensite phases are also formed in TMAZ and HAZ. Thus, it is believed that fine and equiaxial grains in WZ play a more important role on the strengthening mechanisms compared to $\alpha^{\prime}$ martensite phase. The microhardness of $\mathrm{WZ}$ is improved through the finecrystalline strengthening. In addition, the microhardness in TMAZ and HAZ is reduced due to the increment of grains size and the decrement of fraction of $\alpha^{\prime}$ martensite phase. The lowest microhardness is located in BM, whose hardness value is approximately $350 \mathrm{HV}$.

\subsubsection{Tensile Property}

The tensile tests of TA19 welded joints are carried out at both room temperature and high temperature of $480{ }^{\circ} \mathrm{C}$. The fractured tensile specimens and tensile strength of TA19 welded joint are shown in Figures 13, 14 and 15,

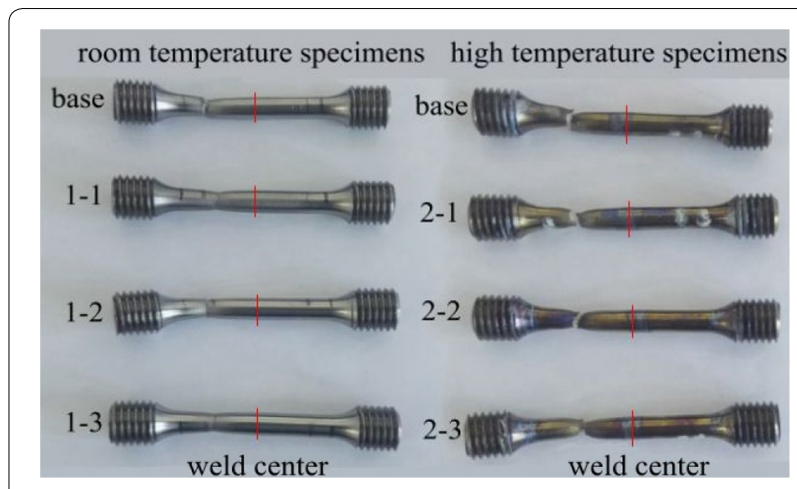

Figure 13 View of tensile specimens after tests

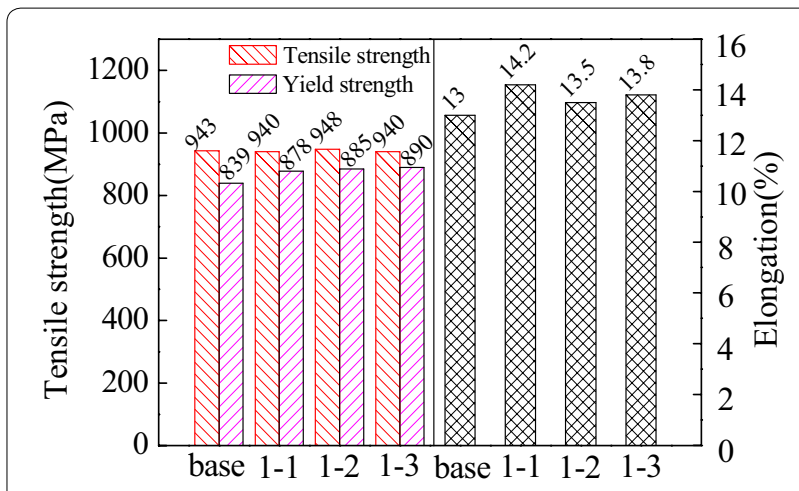

Figure 14 Tensile mechanical properties at room temperature

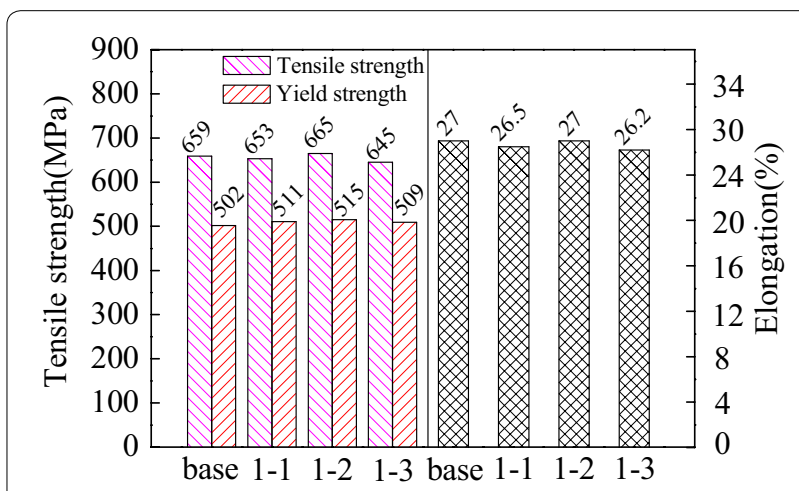

Figure 15 Tensile mechanical properties at $480^{\circ} \mathrm{C}$ high temperature

respectively. It can be clearly seen that all tensile specimens fail in the BM away from center line of WZ. The phenomenon shows that the tensile strength of welded joints is higher than that of the BM. The average tensile strengths of specimens are approximately $943 \mathrm{MPa}$ and $654 \mathrm{MPa}$ at room temperature and high temperature of $480{ }^{\circ} \mathrm{C}$, respectively. The strength values are basically consistent with those of the BM. In addition, the average yield strength and elongation are $884 \mathrm{MPa}$ and $13.8 \%$ at 
room temperature, and $512 \mathrm{MPa}$ and $26.6 \%$ at high temperature of $480^{\circ} \mathrm{C}$, respectively.

The test results show that the welded joints of TA19 alloy exhibit excellent tensile strength property at room temperature and high temperature of $480{ }^{\circ} \mathrm{C}$. The outstanding performance of welded joints should be attributed to the fine-crystalline strengthening in WZ. This is because compared with the $\mathrm{BM}$, the dislocation motion resistance is enhanced owing to the formation of massive grain boundary. Furthermore, the (-12-10) crystal plane of [-12-10] direction of perpendicular to texture in WZ is parallel to the axial tensile force of welded specimens. However, (-12-10) crystal plane isn't the closely packed crystal plane in the active slip systems of close-packed hexagonal structure. So the atomic attraction of adjacent crystal plane of (-12-10) is bigger than that of active slip systems. Thus, the tensile property of welded joints will also be enhanced through the formation of weak texture with [-12-10] direction.

Figures 16 and 17 present the fracture morphology of typical tensile specimen No. 1-1 and No. 2-1, respectively. The quasi-cleavage fracture pattern is exhibited in Figures 16(a) and 17(a) due to the overall fracture morphology of relatively roughness, which indicates a greater proportion in ductile fibers fracture. It can be seen that the size and depth of ductile dimples in center zone are larger than those in the edge zone, as shown in Figures 16(b and c), 17(b and c), respectively. In addition, the fracture morphology has obvious tearing ridges, which demonstrate a hybrid ductile and brittle fracture mode owing to the poor plasticity at room temperature. Figure 17(a) exhibits fracture morphology of typical cup shape which has evident fiber zone. The cup-shaped shear lip of the fracture is wider. Furthermore, the toughening dimples at bottom of the cup are also larger and deeper, which indicate that the BM has a better plasticity at $480{ }^{\circ} \mathrm{C}$.

\section{Conclusions}

(1) TA19 alloy exhibited good weldability in IFW process. The grain morphology in weld zone was the fine and equiaxial grains with the size range of about $15-20 \mu \mathrm{m}$. The microstructure was composed of acicular $\alpha^{\prime}$ martensite phase, a few $\alpha_{p}$ phase and metastable $\beta$ phase. A weak texture with [-12-10] direction was found in the weld zone due

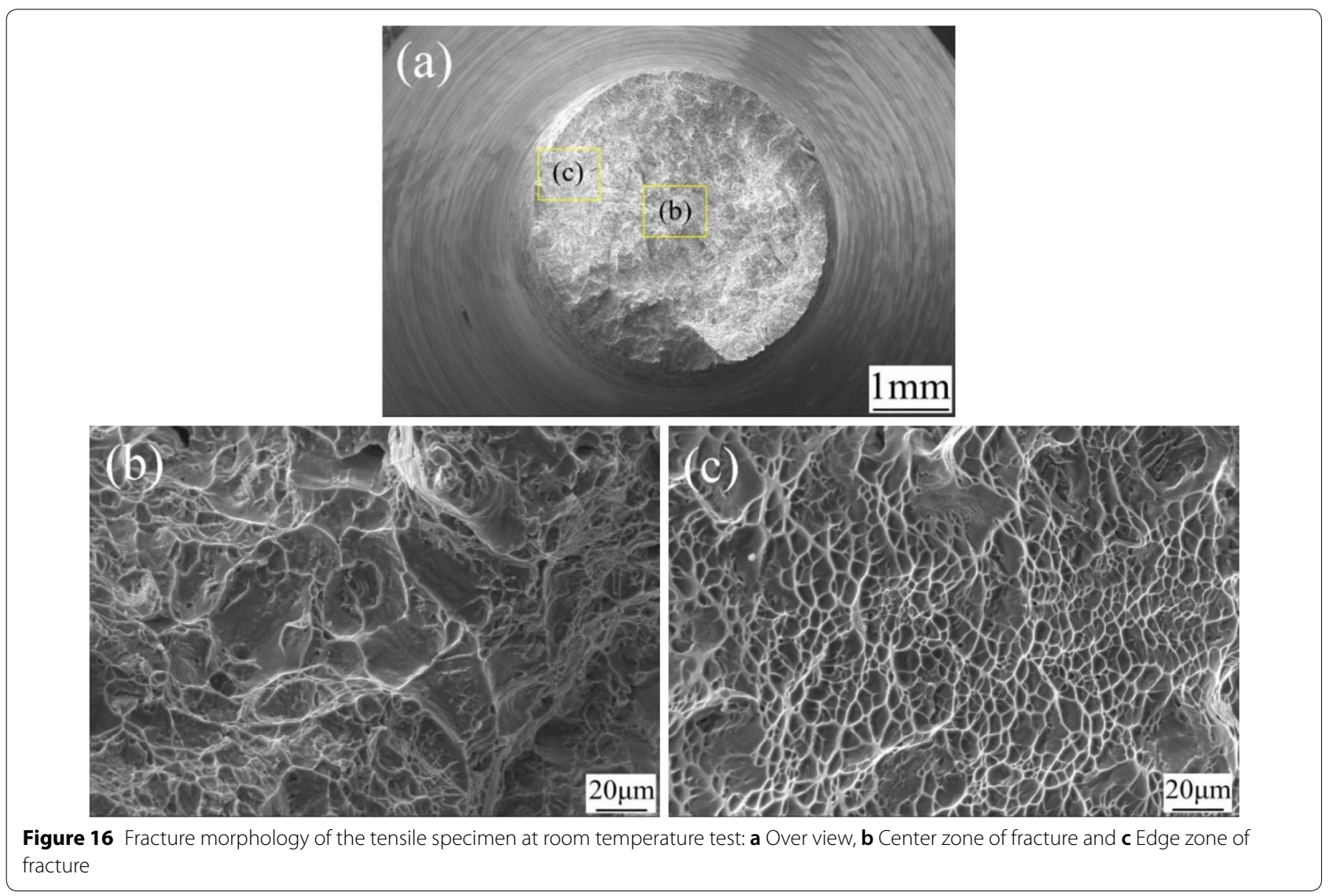



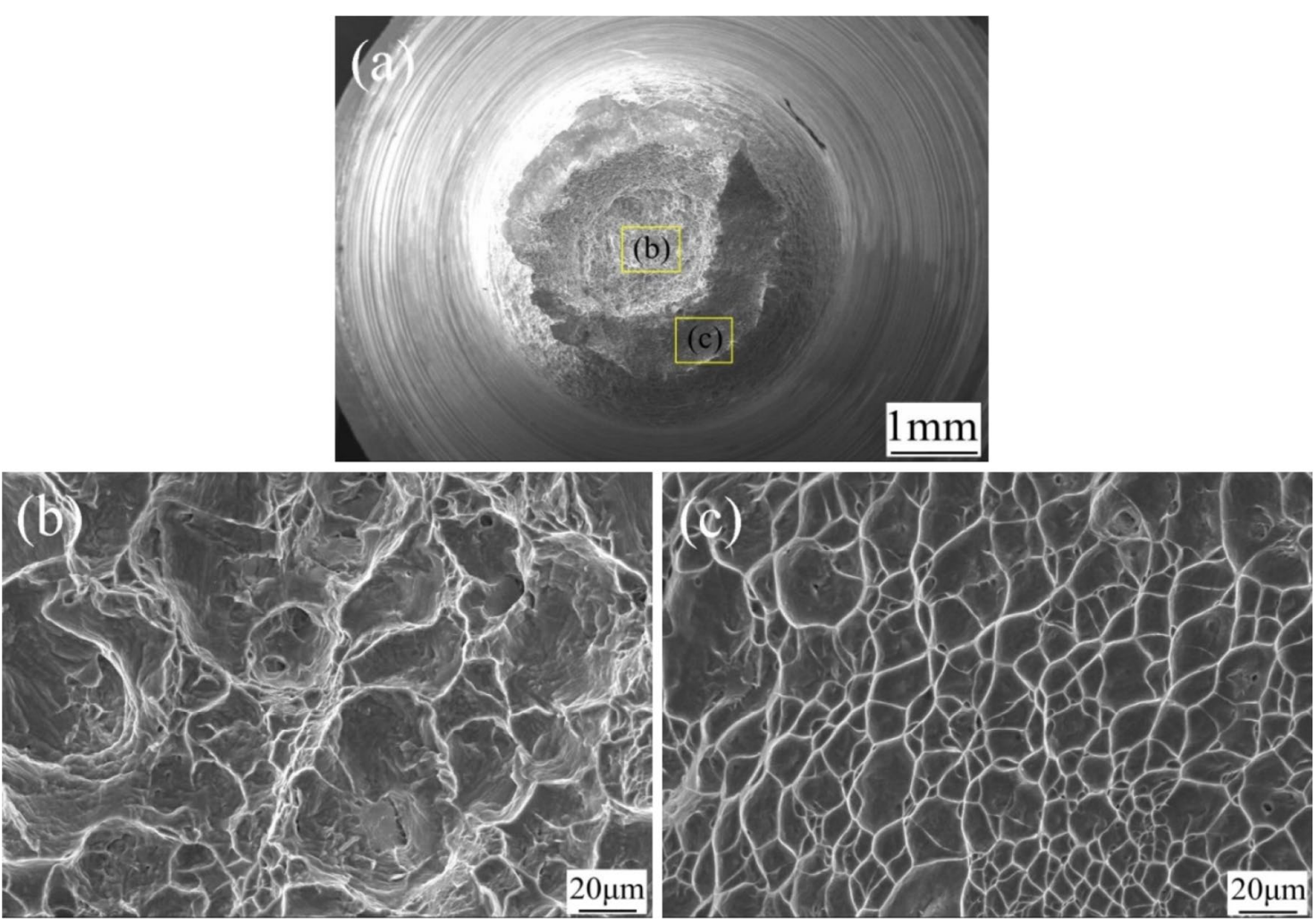

Figure 17 Fracture morphology of the tensile specimen at high temperature of $480^{\circ} \mathrm{C}$ test: a Over view, $\mathbf{b}$ Center zone of fracture and $\mathbf{c}$ Edge zone of fracture

to dynamic recrystallization caused by high temperature and plastic deformation.

(2) The lath-shaped $\alpha_{s}$ and $\beta$ phase in TMAZ and HAZ had been transformed into acicular $\alpha^{\prime}$ martensite phase and metastable $\beta$ phase. The phenomenon of grain growth was observed in HAZ due to outward expansion of grain boundary, which indicated that excessive energy was inputted.

(3) The WZ had the highest microhardness, which decreased gradually from weld zone to base metal. Tensile specimens were all fractured in base metal, which showed that the welded joint owned higher tensile strength compared to the base metal due to fine crystal strengthening and the weak texture with [-12-10] direction. The average tensile strength of welded joint was $943 \mathrm{MPa}$ and $654 \mathrm{MPa}$ at room temperature and high temperature of $480{ }^{\circ} \mathrm{C}$, respectively.

\section{Acknowledgements}

Not applicable

\section{Authors' Contributions}

YW was in charge of the whole trial and wrote the manuscript; JZ was in charge of guidance; CZ, WL and YL assisted with sampling and laboratory analyses. All authors read and approved the final manuscript.

\section{Authors' Information}

Yanquan Wu, born in 1991, is currently an assistant engineer at Research and Development Center, Harbin Welding Institute Limited Company, China. He received his master degree from Harbin Welding Institute, China, in 2019. His research interests include inertial friction welding and Nondestructive testing of titanium alloy.

Chunbo Zhang, born in 1986, is currently a PhD candidate at China Academy of Machinery Science and Technology Group Co., Ltd. He received his bachelor degree from Shenyang University of Technology, China, in 2009. His research interests include friction welding process and equipment.

Jun Zhou, born in 1963, is currently a professor and a PhD candidate supervisor at Research and Development Center, Harbin Welding Institute Limited Company, China. His research interests include friction welding process and equipment.

Wu Liang, born in 1993, is a master candidate at Harbin welding institute, China. He received his bachelor degree from Lanzhou University of Technology, China, in 2017. His research interest is linear friction welding.

Yunlei Li, born in 1984, is currently an engineer at Research and Development Center, Harbin Welding Institute Limited Company, China. He received his 
bachelor degree from Heilongjiang University of Science and Technology, China, in 2008. His research interests include Industrial automatic control.

\section{Funding}

Supported by Natural Science Foundation to Basic Research in Key Areas of Heilongjiang Province of China (Grant No. TD2020E002).

\section{Competing Interests}

The authors declare no competing financial interests.

\section{Author Details}

${ }^{1}$ Research and Development Center, Harbin Welding Institute Limited Company, Harbin 150028, China. ${ }^{2}$ China Academy of Machinery Science and Technology Group Co., Ltd, Beijing 100044, China.

Received: 12 May 2020 Revised: 1 October 2020 Accepted: 10 November 2020

Published online: 30 November 2020

\section{References}

[1] Y G Zhou, W D Zeng, H Q Yu. An investigation of a new near-beta forging process for titanium alloys and its application in aviation components. Materials Science \& Engineering A, 2005, 393(1-2): 204-212.

[2] H Yang, X G Fan, Z C Sun, et al. Recent developments in plastic forming technology of titanium alloys. Science China Technological Sciences, 2011, 54(2): 490-501.

[3] M Jasiczek, D Szcześniak, J Kaczorowski, et al. Investigation of fatigue failures of titanium alloy blades used in compressor modules of aeroderivative industrial gas turbines. Journal of Failure Analysis \& Prevention, 2013, 13(6): 689-696.

[4] S B Gabriel, JV P Panaino, I D Santos, et al. Characterization of a new beta titanium alloy, Ti-12Mo-3Nb, for biomedical applications. Journal of Alloys \& Compounds, 2012, 536(supp_S1): S208-S210.

[5] R R Boyer. An overview on the use of titanium in the aerospace industry. Materials Science \& Engineering A, 1996, 213(1-2): 103-114.

[6] A Pramanik, G Littlefair. Machining of titanium alloy (Ti-6Al-4V)—-theory to application. Machining Science \& Technology, 2015, 19(1): 1-49.

[7] ZX Zhang, S J Qu, A H Feng, et al. Achieving grain refinement and enhanced mechanical properties in Ti-6Al-4V alloy produced by multidirectional isothermal forging. Materials Science \& Engineering A, 2017.

[8] K Fahangdoost, JW Provan. A stochastic systems approach to fatigue reliability-an application to Ti-6Al-4V. Engineering Fracture Mechanics, 1996, 53(5): 687-706.

[9] PV Neminathan, M S Velpari, S R A Rao, et al. Development of ring forgings in Ti-6Al-4V alloy for aero-engine applications. Transactions of the Indian Institute of Metals, 2008, 61(5): 355-361.

[10] S V S N Murty, N Nayan, P Kumar, et al. Microstructure-texture-mechanical properties relationship in multi-pass warm rolled Ti-6Al-4V alloy. Materials Science \& Engineering A, 2014, 589: 174-181.

[1 1] Hewitt, Davies, Thomas, et al. Titanium alloy developments for aeroengine fan systems. Materials Science and Technology, 2014, 30(15): 1919-1924

[12] J M Cai, CX Cao. Alloy design and application expectation of a new generation $600{ }^{\circ} \mathrm{C}$ high temperature titanium alloy. Journal of Aeronautical Materials, 2014, 34(4): 27-36.

[13] J M Cai, G B Mi, F Gao, et al. Research and development of some advanced high temperature titanium alloys for aero-engine. Journal of Materials Engineering, 2016, 44(8): 1-10.

[14] J J Dai, JY Zhu, C Z Chen, et al. High temperature oxidation behavior and research status of modifications on improving high temperature oxidation resistance of titanium alloys and titanium aluminides: A review. Journal of Alloys \& Compounds, 2016, 685: 784-798.

[15] P L Narayana, S W Kim, J K Hong, et al. Tensile properties of a newly developed high-temperature titanium alloy at room temperature and $650{ }^{\circ} \mathrm{C}$. Materials Science \& Engineering A, 2018, 718: 287-291.

[16] E D Nicholas, W M Thomas. A review of friction processes for aerospace applications. International Journal of Materials \& Product Technology, 1998, 13(1/2): 45-55.
[17] X L Dang. The achievements of advanced manufacturing techniques in aviation and aerospace industries. International Journal of Plant Engineering and Management, 2012, 17(3): 145-152.

[18] A Chamanfar, M Jahazi, J Cormier. A review on inertia and linear friction welding of Ni-based superalloys. Metallurgical \& Materials Transactions A, 2015, 46(4): 1639-1669.

[19] Bennett, J Christopher. Inertia friction welding of high strength aerospace alloys. University of Nottingham, 2007.

[20] S Ji, J G Liu, L G Zhang, et al. Effect of welding process parameters on material flow behavior of FGH96 alloy in inertia friction welding. Journal of Mechanical Engineering, 2012, 48(12): 69-74. (in Chinese)

[21] O N Senkov, D W Mahaffey, S L Semiatin, et al. Inertia friction welding of dissimilar superalloys Mar-M247 and LSHR. Metallurgical \& Materials Transactions A, 2014, 45(12): 5545-5561.

[22] J S Tiley, D W Mahaffey, T Alam, et al. Strengthening mechanisms in an inertia friction welded nickel-base superalloy. Materials Science \& Engineering A, 2016, 662: 26-35.

[23] R P Turner, D Howe, B Thota, et al. Calculating the energy required to undergo the conditioning phase of a titanium alloy inertia friction weld. Journal of Manufacturing Processes, 2016, 24(PT.1): 186-194.

[24] W A Baeslack, D Phillips, C English, et al. Inertia-friction welding of an advanced rapidly solidified titanium alloy. Journal of Materials Science Letters, 1991, 10(23): 1401-1408.

[25] J Zhou, Y Q Wu, C B Zhang, et al. Analysis of microstrctures and properties of $\mathrm{Ti}_{2} \mathrm{AlNb}$ intermetallic compound inertia friction welded joints. Transactions of the China Welding Institution, 2018, 39(11): 27-32. (in Chinese)

[26] M M Attallah. Welding and joining of aerospace materials || Inertia friction welding (IFW) for aerospace applications. Welding \& Joining of Aerospace Materials, 2012: 25-74

[27] H S Jeong, J R Cho, J S Oh, et al. Inertia friction welding process analysis and mechanical properties evaluation of large rotor shaft in marine turbo charger. International Journal of Precision Engineering \& Manufacturing, 2010, 11(1): 83-88.

[28] W Guo, G You, G Yuan, et al. Microstructure and mechanical properties of dissimilar inertia friction welding of 7A04 aluminum alloy to AZ31 magnesium alloy. Journal of Alloys \& Compounds, 2016, 695: 3267-3277.

[29] Y H Liu, Z B Zhao, C B Zhang, et al. Thermal and mechanical induced texture evolution of inertia friction welding in $\alpha+\beta$ titanium alloy. Materials Letters, 2020, 277:128329.

[30] D Ballat-Durand, S Bouvier, M Risbet, et al. Through analysis of the microstructure changes during linear friction welding of the near-a titanium alloy Ti-6Al-2Sn-4Zr-2Mo(Ti6242) towards microstructure optimization. Materials Characterization, 2019, 151: 38-52.

[31] R Palanivel, I Dinaharan, R F Laubscher. Assessment of microstructure and tensile behavior of continuous drive friction welded titanium tubes. Materials Science \& Engineering A, 2017, 687(27): 249-258.

[32] J Y Li, Q Liao, W Li. Study on microstructure and properties of TA19 large size titanium alloy bar. Hot Working Technology, 2015, 44(17): 146-148. (in Chinese)

[33] M L Han, P W Xu, M P Wan, et al. Semi-equiaxed structure and tensile properties of TA19 titanium alloy. Rare Metal Materials and Engineering, 2018, 47(12): 3768-3775. (in Chinese)

[34] J W Xu, L H Bian, Q Xue, et al. Effect of solution temperature on microstructure and mechanical properties of TA19 titanium alloy. Titanium Industry Progress, 2015, 32(6): 27-30. (in Chinese)

[35] Q L Niu, X J Cai, Z Q Liu, et al. Wear behavior of carbide inserts in face milling TA19 alloy. Advanced Materials Research, 2012, 426: 339-343.

[36] D Li, K Wang, Z Yan, et al. Evolution of microstructure and tensile properties during the three-stage heat treatment of TA19 titanium alloy. Materials Science \& Engineering A, 2018, 716: 157-164.

[37] KWang, D Sun, Y Wu, et al. Correlation between flow behavior and microstructure evolution during $\alpha / \beta$ deformation of TA 19 titanium alloy. Advanced Engineering Materials, 2016, 18(10): 1808-1815.

[38] L Song, J J Yang, T F Chen. Fatigue test of electron beam welding for TA19 in civil aircraft engine. Journal of Aerospace Power, 2015, 30(1): 121-128.

[39] J Zhang, T C Zhang, L I Li. Study on microstructure and microhardness of linear friction welded joints of TA19 titanium alloy. Hot Working Technology, 2017, 46(17): 59-63. (in Chinese)

[40] C B Zhang, Y Q Wu, D G Piao, et al. Inertia friction welding procedure of TA19 titanium alloy. Transactions of the China Welding Institution, 2018, 39(12): 44-48. (in Chinese) 
[41] M M Attallah, M Preuss, C Boonchareon, et al. Microstructural and residual stress development due to inertia friction welding in Ti-6246. Metallurgical \& Materials Transactions A, 2012, 43(9): 3149-3161.

[42] R Palanivel, I Dinaharan, R F Laubscher. Assessment of microstructure and tensile behavior of continuous drive friction welded titanium tubes. Materials Science \& Engineering A, 2017, 687: 249-258.

[43] X Chen, F Q Xie, T J Ma, et al. Microstructure evolution and mechanical properties of linear friction welded $\mathrm{Ti}_{2} \mathrm{AlNb}$ alloy. Journal of Alloys \& Compounds, 2015, 646: 490-496.

[44] R P Turner, D Howe, B Thota, et al. Calculating the energy required to undergo the conditioning phase of a titanium alloy inertia friction weld. Journal of Manufacturing Processess, 2016, 24(PT.1): 186-194.
[45] A Foul, C A Jr, B Q Guo, et al. Dynamic transformation of $a \rightarrow \beta$ titanium at temperatures below the $\beta$-transus in commercially pure titanium. Materials Science \& Engineering A, 2018, 722(apr.11): 156-159.

[46] Y Su, W Y Li, XY Wang, et al. On microstructure and property differences in a linear friction welded near alpha titanium alloy joint. Journal of Manufacturing Processes, 2018, 36(DEC.): 255-263.

[47] WY Li, T J Ma, S Q Yang, Microstructure evolution and mechanical properties of linear friction welded Ti-5Al-2Sn-2Zr-4Mo-4Cr (Ti17) titanium alloy joints. Advanced Engineering Materials, 2010, 12(1-2): 35-43.

\section{Submit your manuscript to a SpringerOpen ${ }^{\circ}$ journal and benefit from:}

- Convenient online submission

- Rigorous peer review

- Open access: articles freely available online

- High visibility within the field

- Retaining the copyright to your article

Submit your next manuscript at $\boldsymbol{\nabla}$ springeropen.com 